\title{
Reversed sex roles and parental energy investment in zygotes of two pipefish (Syngnathidae) species
}

\author{
Anders Berglund, Gunilla Rosenqvist \& Ingrid Svensson \\ Department of Zoology, Uppsala University, P.O. Box 561, S-751 22 Uppsala, Sweden
}

\begin{abstract}
In pipefishes, males brood their offspring on their body or in a brood pouch. In 2 species of pipefish, Siphonostoma typhle and Nerophis ophidion, sexual dimorphism, dichromatism, and sex role reversal differed in degree between the species. $N$. ophidion females were larger than males, whereas in $S$. typhle sexes were equally large. Furthermore, $N$. ophidion females have pronounced sexual colourings and possess dorso-ventral skin folds, in contrast to males, whereas sexes in $S$. typhle look alike. The hypothesis that the males in the more reversed sex dimorphic species, $N$. ophidion, should invest relatively more energy in their young than the males of the species with smaller differences in sex roles and sex dimorphism was investigated by measuring energy contents in adults and different zygote stages as well as in vitro respiration of zygotes, also of different stages. Our results showed that in both species males provide nourishment to their broods. Contrary to expectation, however, males of $N$. ophidion invest less energy per zygote than do the females, while in $S$. typhle the 2 sexes make about equal investments. The strong dimorphism in $N$. ophidion therefore is likely to have evolved in response to some constraint other than energy investment imposed by males on the female's reproductive success.
\end{abstract}

\section{INTRODUCTION}

If one sex limits the reproductive success of the other, the latter sex may evolve traits enhancing its intrasexual competitive potential and/or attractiveness to the other sex (Darwin 1871, Williams 1966, 1975 , Faugeres et al. 1970, O'Donald 1972). Anisogamy and, among higher vertebrates, high metabolic demands on females when reproducing, tend to make females the limiting resource for male reproductive success. In such a case, males will usually care less for the young, be more active in courtship, be less discriminating in mate choice, be larger, and will possess sexual colourings, as compared to females. This comprises the 'traditional' male sex role. In some animal groups, however, males assume a major portion of the parental burdens, and if a reversal of sex roles and dimorphism patterns can be established in such groups, it would constitute a strong case for the adaptiveness of these roles and patterns (Williams 1975). Such role reversals in birds and mammals in which males provide more parental care has also been documented (Wittenberger 1979, Petrie 1983), as well as in insects where males present a nutritious spermatophore to the female (Gwynne 1981, 1983, 1984).
In pipefishes and seahorses (Syngnathidae), the male receives eggs from the female and then broods the embryos on the ventral body surface or in a brood pouch. Subsequently he releases live offspring. Obviously there is a physical limit to the number of eggs a male can accomodate, and males therefore to some extent may be the limiting sex in the above sense. Accordingly, sex role reversal has been recorded for a number of species in this family (Fiedler 1954, Herald 1961, Breder \& Rosen 1966, Gronell 1984).

The degree of sex role reversal differs among pipefish species, however. We have utilized such interspecific differences in order to investigate one of the ways by which a male may be a limiting resource to the female; we have also questioned whether the male is more limiting in the species with the greater differences in sex roles. There are several ways in which a male may be a limiting factor, however. One class of constraints imposed by the male on the female relates to energetic circumstances: (i) The male's investment of energy in each zygote reared to independence may be larger than that of the female (Trivers 1972). This possibility will be examined in this paper. (ii) The male may invest more energy per unit time during some critical period of time such as the breeding sea- 
son. (iii) In seasonally spawning pipefish species, the periods during which males and females invest energy in reproduction usually do not coincide: females produce eggs during winter, spring and summer, whereas males rear them during summer only. If the pay-off (energy-efficiency) of energy investment is lower under the higher summer temperatures, or if conflicting demands (e.g. somatic growth) occur during summer, males may limit the female's reproductive success. (iv) If the rearing of offspring by the males inflicts higher costs than does producing eggs (for instance, due to lowered feeding capacity or increased predator susceptibility), then again males may be limiting.

A second class of male-imposed constraints on female reproductive success concerns rearing capacity: if females produce more eggs per unit time than males can handle, or if females outnumber males, more eggs will be around in the population than males can care for (Emlen \& Oring 1977). Also, if a high variation in male quality exists, a shortage of high quality males may arise and limit female reproductive success (Petrie 1983). We have to some extent considered these possibilities too.

The 2 species we have examined, Nerophis ophidion (L.) and Siphonostoma typhle (L.) (= Syngnathus typhle), occur in the same habitat, i.e. Zostera marina (L.) meadows along the Atlantic and Mediterranean coasts of Europe (Fiedler 1954, Kähnsbauer 1974 , Wheeler 1978). Our study site is located on the Swedish west coast, where season has pronounced effects on breeding. In $N$. ophidion the young are reared openly on the male's ventral abdomen, whereas $S$. typhle males carry their young in a ventrally located brood pouch. As we will show, sexual size dimorphism in the former species is much larger than in the latter. $N$. ophidion females, in contrast to males, also possess ornaments such as a bright blue colouration on the head and anterior parts of the body, as well as 2 'appearance-enlarging' dorso-ventral skin folds, whereas the $S$. typhle sexes look alike. The blue colouration in $N$. ophidion females is a primary determinant of courtship success (Berglund et al. unpubl.). Similar interspecific differences as in the amount of sexual dimorphism can also be observed in courtship (Fiedler 1954). Our prediction therefore is that males in $N$. ophidion are a more limiting resource to females, compared to $S$ typhle males.

By measuring the energy contents of adults and of zygotes of different stages, as well as zygote respiration during the time of male care, we have compared male and female zygote investment between the 2 species. By measuring the respiration rates of zygotes, i.e. their minimum energy requirements, one can determine whether males actually contribute nourishment to their young, or whether they just guard them.
Some reports (Leiner 1934, Fiedler 1954, Linton \& Soloff 1964) indicated that offspring of syngnathid species (among those Nerophis ophidion) may be hatched in vitro, without male care (albeit with high zygote mortality), while others have found epithelial structures suggesting transport of nourishment to the embryos from the male (Kronester-Frei 1975), and evidence for a transfer of a labeled amino acid to developing young (Haresign \& Schumway 1981).

\section{MATERIAL AND METHODS}

Field samples were collected in shallow $(0.5$ to $6 \mathrm{~m})$ Zostera marina meadows in the Gullmar Fjord on the Swedish west coast $\left(58^{\circ} 15^{\prime} \mathrm{N}, 11^{\circ} 28^{\prime} \mathrm{E}\right)$ during the springs and summers of 1983 and 1984. Animals were captured using a small beam trawl with mesh size $2 \mathrm{~mm}$, pulled by a boat. Pipefishes were killed in a MS 222 (metacain; 3-aminobensoic acid ethylester methane sulfonate) solution and kept frozen until measured. Standard length, numbers and developmental stages of eggs and embryos, dry weight $\left(60^{\circ} \mathrm{C}\right.$ for at least $24 \mathrm{~h}$ ) of body, eggs/embryos, and gonads, and approximate 'fullness' of egg accomodation space in males were recorded subsequently. For energy content determination, samples were combusted in a Phillipson microbomb calorimeter (Prus 1975). At least 2 pellets per body and 1 pellet per clutch were combusted, and the average used in calculations. Samples were obtained from the field. Energy content of offspring was measured in males only, both in what we judged to be newly deposited eggs and in ready-tohatch juveniles. The energy content of ripe eggs in females was assumed to equal that in the eggs of a newly fertilized male, since the energetic contribution of one sperm cell is negligible.

Respiration in embryos was measured by carefully removing them from the male and subsequently placing them in a Winkler bottle. They were allowed to respire for $4 \mathrm{~h}$, during which time mortality (as estimated by eggs turning opaque) was found to be negligible. Oxygen saturated, filtered sea water with a temperature of 18 to $19^{\circ} \mathrm{C}$ and a salinity of 32.0 to $33.8 \%$ was used, these values being in accordance with ambient ones in our sampling areas. Oxygen consumption was analyzed according to standard Winkler methods, using sulphuric instead of hydrochloric acid because of the use of sea water in the bottles. Between 23 and 173 zygotes were placed in each Winkler bottle. From each bottle (volume: 115 to $130 \mathrm{ml}$ ) two $50 \mathrm{ml}$ subsamples were titrated, and the average used in calculations. Three zygote stages, obtained from field samples, were measured: newly fertilized (deposited), half-way mature, and fully 
Table 1. Siphonostoma typhle (S. t.) and Nerophis ophidion (N. o.). Average dry weights in 1983 and 1984 pooled samples of 1-yr-olds

\begin{tabular}{|c|c|c|c|c|c|c|}
\hline Year & Species, sex & Dry weight (mg) & $\mathrm{SD}$ & $\mathrm{n}$ & Student's t & $\mathrm{P}<$ \\
\hline \multirow[t]{2}{*}{1983} & $\begin{array}{l}\text { S. t. female } \\
\text { S. t. male }\end{array}$ & $\begin{array}{l}242.5 \\
229.0\end{array}$ & $\begin{array}{l}126.0 \\
117.1\end{array}$ & $\begin{array}{r}97 \\
116\end{array}$ & 0.806 & ns \\
\hline & $\begin{array}{l}\text { N. o. female } \\
\text { N. o. male }\end{array}$ & $\begin{array}{r}112.1 \\
74.3\end{array}$ & $\begin{array}{l}51.1 \\
24.9\end{array}$ & $\begin{array}{l}77 \\
79\end{array}$ & 5.509 & 0.001 \\
\hline \multirow[t]{2}{*}{1984} & $\begin{array}{l}\text { S.t. female } \\
\text { S.t. male }\end{array}$ & $\begin{array}{l}317.3 \\
297.4\end{array}$ & $\begin{array}{l}155.0 \\
152.5\end{array}$ & $\begin{array}{l}123 \\
114\end{array}$ & 0.993 & ns \\
\hline & $\begin{array}{l}\text { N. o. female } \\
\text { N. o. male }\end{array}$ & $\begin{array}{l}167.1 \\
104.1\end{array}$ & $\begin{array}{l}57.3 \\
34.3\end{array}$ & $\begin{array}{l}48 \\
61\end{array}$ & 7.085 & 0.001 \\
\hline
\end{tabular}

mature ones. Length of pregnancy was estimated to be $24 \mathrm{~d}$ in both species according to observations in aquaria. In aquaria, fishes were fed Artemia nauplii and adults.

In our calculations of size dimorphism and sex ratios, and in all energetic studies, we employed only specimens estimated to be 1 yr of age. Age was estimated from size (dry weight)-frequency relations, where invariably $1 \mathrm{yr}$-old individuals greatly predominated. One-year-old Siphonostoma typhle males and females weighed from 50 to $750 \mathrm{mg}$; Nerophis ophidion males weighed from 20 to $260 \mathrm{mg}$ and females from 20 to $300 \mathrm{mg}$. All statistical probabilities given are 2-tailed.

\section{RESULTS}

The 2 species differed greatly in terms of sexual size dimorphism (Table 1): males and females were of equal weight in Siphonostoma typhle, whereas in Nerophis ophidion females were heavier than males by a factor of $1.5: 1$ to $1.6: 1$ during both 1983 and 1984 .

Growth increments were small during the sampling periods, which justifies pooling the samples from the whole season. If each sample is analyzed individually, however, the same pattern still emerges.

Sex ratios did not differ significantly from equality in either species during the $2 \mathrm{yr}$ (binomial test corrected for continuity; Siphonostoma typhle 1983: $\mathrm{P}=0.219$, 1984: $\mathrm{P}=0.630 ;$ Nerophis ophidion 1983: $\mathrm{P}=0.939$, 1984: $\mathrm{P}=0.250)$.

Energy content per unit weight in body tissue (i.e. the entire fish except reproductive tissue) and in the 2 different zygote stages (Table 2) was closely similar in the 2 species. Eggs did not decrease markedly in energy content per unit weight during pregnancy, but as egg weight decreased during the same period of time, there was a noticeable total energy loss per egg, amounting to about $1.2 \mathrm{~J}$ in either species (Table 3 ).
Table 2. Siphonostoma typhle (S. t.) and Nerophis ophidion (N.o.). Energy content per unit dry weight in adult bodies, and in newly deposited (nd) and mature (m) zygotes

\begin{tabular}{|llcrr|}
\hline Species & \multicolumn{1}{c}{ Tissue } & Energy $\left(\mathrm{J} \mathrm{mg}^{-1}\right)$ & $\mathrm{SD}$ & $\mathrm{n}$ \\
\hline S.t. & Female, body & 18.22 & 1.11 & 10 \\
& Male, body & 17.80 & 2.75 & 29 \\
& nd zygotes & 25.22 & 2.89 & 7 \\
& m zygotes & 24.07 & 2.32 & 10 \\
N. o. & Female, body & 18.38 & 2.06 & 10 \\
& Male, body & 17.23 & 1.44 & 21 \\
& nd zygotes & 24.68 & 2.65 & 8 \\
& m zygotes & 23.93 & 4.10 & 11 \\
\hline
\end{tabular}

The energy loss was, however, not significant in Siphonostoma typhle eggs (Student's t-test, $t=0.802$, $\mathrm{DF}=26$, as compared to Nerophis ophidion: $\mathrm{t}=3.412$, $\mathrm{DF}=18, \mathrm{P}<0.01$ ). There were no significant correlations between body weight of the parent and energy content per egg in either species.

If the energy loss due to zygote respiration is greater than $1.2 \mathrm{~J}$, the father must have contributed energy to the embryos. Our respiration measurements demonstrated that this was the case in both species: when total oxygen consumption is calculated from the oxygen consumption per unit time (Fig. 1), and converted to energy $\left(1 \mathrm{ml} \mathrm{O}_{2} \mathrm{~h}^{-1}=20.08 \mathrm{~J} \mathrm{~h}^{-1}\right.$, Gnaiger \& Forstner 1983), it turns out that a Siphonostoma typhle zygote on average consumed $21.2 \mathrm{~J}$ and a Nerophis ophidion zygote $2.19 \mathrm{~J}$, assuming a $24 \mathrm{~d}$ pregnancy in both species. Thus, a $S$. typhle male contributed on average $20.0 \mathrm{~J} \mathrm{zygote}^{-1}$ and a $N$. ophidion male $0.96 \mathrm{~J}$ zygote $^{-1}$. The difference between the 2 species in zygote energy consumption and paternal energy contribution is due to the much smaller size of a $N$. ophidion zygote (Table 3 ). There were no significant correlations between male body weight and respiration zygote $^{-1}$ in either species. 
Table 3. Siphonostoma typhle (S.t.) and Nerophis ophidion (N. o.). Weight and energy decrease per zygote during pregnancy. nd: newly deposited zygotes; $m$ : mature zygotes. $P$ according to Student's t-test

\begin{tabular}{|c|c|c|c|c|c|c|}
\hline \multirow[t]{2}{*}{ Species } & \multicolumn{3}{|c|}{ Weight of zygote (ug) } & \multicolumn{3}{|c|}{ Energy of zygote $(\mathrm{J})$} \\
\hline & nd & $\mathrm{m}$ & $\mathrm{P}<$ & nd & $\mathrm{m}$ & $\mathrm{P}<$ \\
\hline S.t. mean & 941.6 & 933.8 & ns & 23.74 & 22.53 & ns \\
\hline $\mathrm{SD}$ & 73.3 & 95.1 & & 3.12 & 3.51 & \\
\hline $\mathrm{n}$ & 7 & 10 & & 7 & 10 & \\
\hline N.o. mean & 189.3 & 144.6 & 0.01 & 4.648 & 3.417 & 0.01 \\
\hline SD & 10.2 & 27.7 & & 0.472 & 0.888 & \\
\hline $\mathrm{n}$ & 10 & 12 & & 8 & 12 & \\
\hline
\end{tabular}

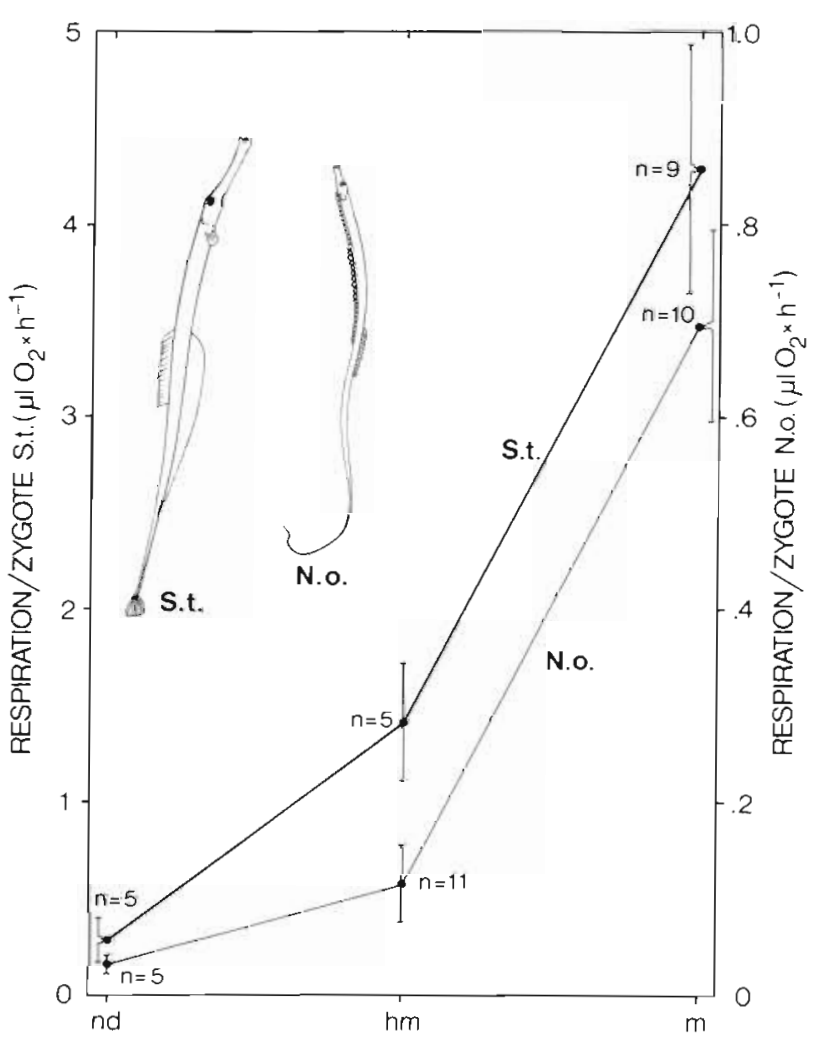

Fig. 1. Siphonostoma typhle (S.t.) and Nerophis ophidion (N.o.). Oxygen consumption in zygotes at 3 developmental stages: newly deposited (nd), half mature (hm) and mature (m). Standard deviations are drawn and number of clutches measured (n) given. Each clutch contains 23 to 173 zygotes

Now, which sex incurs a higher zygote energy investment cost, and how do the 2 species differ in this respect? A ratio of (energy invested in 1 zygote) : (body energy content) was calculated using dry body weights from individuals sampled during 1983 and 1984, and only specimens aged as 1 -yr-old and containing a full egg/zygote load were used. As a Siphonostoma typhle female spawns repeatedly, it may be difficult to determine whether she possesses a full ovary or not, but individuals having unrealistically low egg numbers for their body weights were excluded from the analysis. Data were pooled within years. In S. typhle we found no differences between males and females with regard to the investment in 1 zygote, whereas in Nerophis ophidion females invested more (Table 4). This is concordant with the fact that in $S$. typhle eggs did not

Table 4. Siphonostoma typhle (S. t.) and Nerophis ophidion (N.o.). Average zygote investment ratios (ZIR) of (energy invested per zygote):(body energy content in 1 -yr-olds in field samples from the $2 \mathrm{yr}$. All specimens involved were carrying a full clutch. P according to Mann-Whitney U-test

\begin{tabular}{|llllll|}
\hline Year & Species, sex & ZIR $\times 10^{3}$ & SD & $\mathrm{n}$ & $\mathrm{P}$ \\
\hline 1983 & S.t.fernale & 5.67 & 2.14 & 72 & 0.756 \\
& S.t. male & 5.66 & 2.02 & 76 & \\
& N.o.female & 1.50 & 0.35 & 21 & $<0.00006$ \\
& N.o. male & 0.58 & 0.08 & 18 & \\
1984 & S.t.female & 4.43 & 1.91 & 73 & 0.390 \\
& S.t. male & 4.62 & 3.42 & 25 & \\
& N. o. female & 1.32 & 0.34 & 14 & \\
& N.o. male & 0.50 & 1.14 & 27 & $<0.00006$ \\
& & & & & \\
\hline
\end{tabular}

decrease significantly in energy content during pregnancy, whereas this decrease in $N$. ophidion was indeed significant (Table 3).

Males of the 2 species can be compared if another ratio is calculated: energy investment in entire clutch per unit body energy content. Using the same specimens as above, it turns out that Siphonostoma typhle males had a higher clutch investment ratio than had Nerophis ophidion males in both years (Table 5).

As mentioned, no correlations between parental body weight and energy content per zygote or zygote respiration was observed. This does not prove that such correlations never exist, because we have only analyzed 1-yr-old individuals of a fairly restricted size range. In fact, when all year classes in a field sample are analyzed, it turns out that in Siphonostoma typhle a 
Table 5. Siphonostoma typhle (S.t.) and Nerophis ophidion (N.o.). Average energy investment in a clutch per unit body energy content (clutch investment ratio, CIR) in 1-yr-old males in field samples from 2 yr. $\mathrm{P}$ according to MannWhitney U-test

\begin{tabular}{|cccccc|}
\hline Year & Species & CIR & SD & n & P $<$ \\
\hline \multirow{2}{*}{1983} & S.t. & 0.3325 & 0.1339 & 77 & \\
& N.o. & 0.0952 & 0.0211 & 18 & 0.00006 \\
& & & & & \\
1984 & S.t. & 0.2807 & 0.1244 & 24 & 0.00006 \\
& N.o. & 0.0555 & 0.0207 & 27 & \\
\hline
\end{tabular}

significant correlation between male body weight and weight of 1 zygote existed both in $1983(\mathrm{r}=0.275, \mathrm{n}=$ 63, $\mathrm{P}<0.05)$ and $1984(\mathrm{r}=0.505, \mathrm{n}=28, \mathrm{P}<0.01)$, whereas no significant relations were found in Nerophis ophidion (1983: $\mathrm{r}=0.062, \mathrm{n}=12$, n.s.; 1984: $\mathrm{r}=0.059, \mathrm{n}=18, \mathrm{n.s}$.$) . Similarly, a correlation$ between male weight and numbers of eggs in a male carrying a full clutch was found in $S$. typhle (1983: $\mathrm{r}=$ $0.728, \mathrm{n}=76, \mathrm{P}<0.001 ; 1984: \mathrm{r}=0.599, \mathrm{n}=24, \mathrm{P}=$ 0.002 ) but not in $N$. ophidion (1983: $\mathrm{r}=0.154, \mathrm{n}=18$, n.s.; 1984: $\mathrm{r}=0.158, \mathrm{n}=27$, n.s.). These correlations suggest that in $S$, typhle, male weight in general is correlated with zygote energy content or respiration rate.

\section{DISCUSSION AND CONCLUSIONS}

Our hypothesis that males invest more resources than do females in offspring in Nerophis ophidion as compared to Siphonostoma typhle was not substantiated by measurements of energy investment per zygote; exactly the opposite was found. This means either that our methods were inadequate, or that $N$. ophidion males limit the reproductive success of females in some other way than by energy transferred to zygotes, or that the hypothesis can be rejected. We will discuss these 3 possibilities in turn.

Admittedly the adequacy of our measurements do rely upon several assumptions, which may be more or less realistic. Firstly, zygotes were removed from males before respiration was measured, the removal constituting an obvious disturbance. Respiration curves of the 2 species are of similar shape, however, and their standard deviations are small in both species (Fig. 1), indicating that this disturbance probably had an equal impact in both species. Furthermore, both in another syngnathid fish species with brood pouch, Hippocampus erectus (Linton \& Soloff 1964), and in Nerophis ophidion (Fiedler 1954), zygotes have been reared in vitro successfully, indicating a considerable endurance after removal from the father.
Secondly, when calculating the ratio of zygote investment to body energy content, we assume that most eggs become fertilized in natural populations, that is, that there is no substantial shortage of male brooding capacity. It is a common procedure to compare ratios such as clutch energy content per body energy content, but as Siphonostoma typhle females usually spread their eggs among several males (Berglund et al. unpubl.) it is difficult to measure their clutch size. We therefore have chosen to compare the ratio (energy investment in 1 zygote) : (body energy content) between 1-yr-old males and females within each species. The ratio will basically reflect the inverted body weight distribution within a sex, but be adjusted for differences in body energy content and zygote investment between sexes. The ratio is not suited for interspecific comparisons, as zygote size differs between the species.

As the sex ratio in Nerophis ophidion was equal and no significant correlation existed between male size and number of eggs nursed, the assumption of $100 \%$ egg fertilization seems valid in this species. Certainly, male quality may vary, so that good mates may be scarce (Petrie 1983), but as most males actually carried offspring (Fig. 2) this may not be of great importance. The sex ratio in Siphonostoma typhle was also equal, as were body weight distributions of the 2 sexes, but if females can produce more eggs than males of equal size can accomodate, the assumption that all eggs become fertilized may be invalid. Because clutch size in females is difficult to estimate (since they may have spawned part of the clutch prior to capture), we have no data with which to assess female egg production vs male egg accomodation space. For an $S$. typhle female to invest proportionally as much as an $N$. ophidion female (i.e about 3 times as much as a male, Table 4), however, her clutch size or numbers of clutches would have to be tripled compared to what a male of that species can accomodate, which is of course highly unlikely. Furthermore, if female egg production was higher than male rearing capacity in $S$. typhle, the habit of $S$. typhle females of laying eggs in several males (Berglund et al. unpubl.) would not be expected; if a female found an empty male she ought to deposit all her ripe eggs in him, given such males were in short supply.

Thirdly, we have assumed that it is possible to pick females of Siphonostoma typhle with full ovaries for the zygote investment: body energy ratio calculations on the basis of plots of egg numbers vs body size. As clutch size is not involved in the ratio itself, however, this is not a crucial assumption. What is involved in the ratio is only body weights from field samples and a number of constants, and as the omitted females (i.e. those with less than full ovaries) did not have a weight 


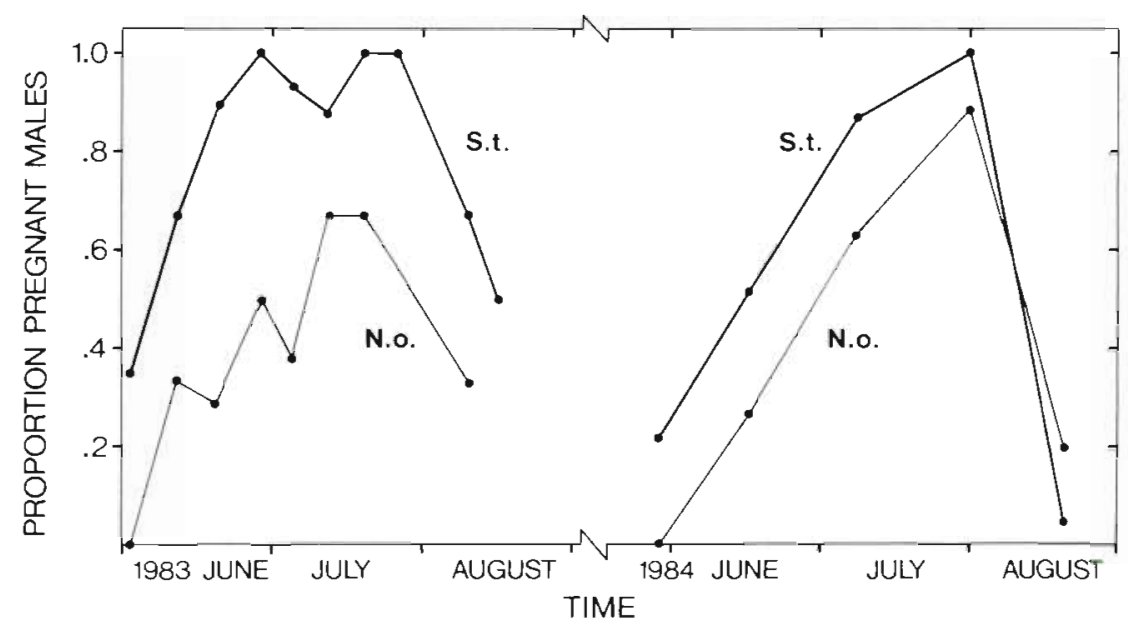

Fig. 2. Siphonostoma typhle (S.t.) and Nerophis ophidion (N.o.). Proportions of pregnant males in field samples distribution different from those included, the investment ratio of $S$. typhle females will not be affected by difficulties in estimating maximal female clutch size.

Fourth, the cost of producing sperm ought to be included in a male's cost of producing offspring. The male gonads of both species, however, were so small and thin as to be almost impossible to dissect or weigh. This is also expected in species lacking sperm competition among males and with a $100 \%$ paternity confidence. Sperm production costs have therefore been omitted in this study.

Fifth, the basis for assuming a $24 \mathrm{~d}$ pregnancy length in both species are some rather limited aquaria observations. As offspring size is much smaller in Nerophis ophidion (Table 3), we would, if any difference in length of pregnancy exists, expect a shorter pregnancy in this species. If so, this would even further decrease the male's investment in a zygote in this species, thus only strengthening our results.

Thus we feel confident in stating that Nerophis ophidion females invested more energy per zygote than did $N$. ophidion males, whereas no such difference could be established in Siphonostoma typhle. A similar pattern was observed in 2 populations of Mormon crickets Anabrus simplex (Gwynne 1984); females from a sex-role reversed population invested (by weight) proportionally more than males, when compared to females from a population showing no sex-role reversal. Furthermore, males from both pipefish species did contribute nourishment to their offspring.

Thus, if the hypothesis is correct, the possibility remains that Nerophis ophidion males are limiting the reproductive success of the females in some other respect than by the amount of energy invested in zygotes. As $N$. ophidion had a shorter breeding season than Siphonostoma typhle (Fig. 2), N. ophidion males may invest more resources per unit time during the breeding season than do the females, which have had all winter and early spring to produce eggs. As the 2 species live in the same habitat, energetic pay-offs and ambient water temperatures are the same, and these factors therefore are less likely to explain the sexual dimorphism of $N$. ophidion. Furthermore, males of both species may be hindered in their movements by the brood and as a result may experience feeding difficulties and/or increased predation pressure. We do not know whether this affects the 2 species differentially. As discussed above, differences in rearing capacity among males of the 2 species are unlikely to explain the patterns in dimorphism.

The possibility remains that the hypothesis is wrong. In Siphonostoma typhle the male has a brood pouch, especially designed to nurse offspring, whereas in Nerophis ophidion the embryos are attached directly to the male's ventral part. Maybe the group of pipefishes to which $S$. typhle belongs is 'designed' to increase male investment in the form of nourishment transfer, whereas this is less true in the $N$. ophidion types of pipefish. Also, S. typhle males did invest more energy in their clutch than did $N$. ophidion males (Table 5). This leaves unexplained, however, the large size, bright colouration, appearance-enlarging skin folds, and active courtship behaviour of $N$. ophidion females. As we by no means have excluded other possibilities for $N$. ophidion males to be a limiting resource, such as energy investment per unit time, the theory of limiting sex and sexual ornaments can not be refuted by this study

What we have shown is that extensive patemal care does not necessarily produce patterns of reversed sexual dimorphisms and sex roles. Such reversed patterns may have more complex explanations than simple patterns of energy investment into offspring.

Acknowledgements. We thank the staffs and directors of Klubban Biological Station and Kristineberg Marine Biological Station for providing help and facilities there, and R. K. 
Monahan, S. Ulfstrand and G. C. Williams for valuable comments on the manuscript. The study was supported by the Swedish Natural Science Research Council and the Théel's foundation

\section{LITERATURE CITED}

Breder, C. M., Rosen, D. E. (1966). Modes of reproduction in fishes. Natural History Press, Garden City, New Jersey

Darwin, C. (1871). The descent of man and selection in relation to sex. John Murray, London

Emlen, S. T., Oring, L. W. (1977). Ecology, sexual selection, and the evolution of mating systems. Science 197 : 215-223

Faugeres, A., Petit, C., Thibout, E. $\{1970\}$. The components of sexual selection. Evolution 25: 265-275

Fiedler, K. (1954). Vergleichende Verhaltensstudien an Seenadeln, Schlangennadeln und Seepferdchen. Z Tierpsychol. 11: 358-416

Gnaiger, E., Forstner, H. (1983). Polarographic oxygen sensors, aquatic and physiological applications. SpringerVerlag, Berlin

Gronell, A. M. (1984). Courtship, spawning and social organization of the pipefish, Corythoichthys intestinalis (Pisces: Syngnathidae) with notes on two congeneric species. $Z$. Tierpsychol. 65: 1-24

Gwynne, D. T. (1981). Sexual difference theory: Mormon crickets show role reversal in mate choice. Science 213: $779-780$

Gwynne, D. T. (1983). Male nutritional investment and the evolution of sexual differences in the Orthoptera. In: Gwynne, D. T., Morris, G. K. (ed.) Orthopteran mating systems: sexual competition in a diverse group of insects. Westview Press, Boulden, p. 337-366

Gwynne, D. T. (1984). Sexual selection and sexual differences in Mormon crickets (Orthoptera: Tettigonidae, Anabrus simplex). Evolution 38: 1011-1022

Haresign, T. W., Shumway, S. E. (1981). Permeability of the marsupium of the pipefish Syngnathus fuscus to $\left[{ }^{14} \mathrm{C}\right]-$ alpha amino isobutyric acid. Comp. Biochem. Physiol. 69A: 603-604

Herald, E. S. (1961). Living fishes of the world. Doubleday, New York

Kähnsbauer, D. (1974). Beitrag zur Kenntnis der Syngnathidaenfauna von Nordeuropa. Ann. Naturhist. Mus. Wien 78: 281-290

Kronester-Frei, A. (1975). Licht- und Elektronenmikroskopische Untersuchungen am Brutepithel des Männchens von Nerophis lumbriciformis (Pennant 1776), Syngnathidae, unter spezieller Berücksichtigung der strukturellen Veränderung der Eihülle. Forma et functio 8: 419-462

Leiner, M. (1934). Der osmotische Druck in den Bruttaschen der Syngnathidaen. Zool. Anz. 11/12: 273-289

Linton, J. R., Soloff, B. L. (1964). The physiology of the brood pouch of the male sea horse Hippocampus erectus. Bull. mar. Sci. Gulf Carrib. 14: 45-61

O'Donald, P. (1972). Natural selection of reproductive rates and breeding times and its effects on sexual selection. Am Nat. $106: 368-379$

Petrie, M. (1983). Female moorhens compete for small fat males. Science 220: 413-415

Prus, T. (1975). Calorimetry and body composition. 5A. Measurement of calorific value using Phillipson microbomb calorimeter. In: Grodzinski, W., Klekowski, R. Z., Duncan A. (ed.) Methods for ecological bioenergetics, IBP handbook no. 24. Blackwell, Oxford, p. 149-160

Trivers, R. L. (1972). Parental investment and sexual selection. In: Campbell, B. (ed.) Sexual selection and the descent of man, 1871-1971. Aldine, Chicago, p. 136-179

Wheeler, A. (1978). Key to the fishes of northern Europe. Warne, New York

Williams, G. C. (1966). Adaptation and natural selection. Princeton University Press, Princeton

Williams, G. C. (1975). Sex and evolution. Princeton University Press, Princeton

Wittenberger, J. F. (1979). The evolution of mating systems in birds and mammals. In: Marler, P., Vanderberg, J. G. (ed.) Handbook of behavioral neurobiology, Vol. 3. Social behaviour and communication. Plenum Press, New York, p. 271-349

This article was presented by Professor J. Gray; it was accepted for printing on December 16, 1985 